\title{
PERANCANGAN SWITCH MANAGEABLE UNTUK PENGELOLAAN VIRTUAL LAN MENGGUNAKAN LINUX CentOS PADA SMKN 2 KURIPAN
}

\author{
Mohammad Taufan Asri Zaen1, Syahadatul Intihan² \\ Program Studi Teknik Informatika \\ Sekolah Tinggi Manajemen Informatika dan komputer (STMIK) Lombok \\ Jln. Basuki Rahmat No.105 Praya Lombok Tengah 83511 \\ ${ }^{1}$ opanzain@gmail.com, ${ }^{2}$ hadaintihan@gmail.com
}

\begin{abstract}
In realizing an integrated service both internally and externally, SMK Negeri 2 Kuripan need a reliable computer network infrastructure and can connect all units in a single integrated network. Current state of computer networks in SMK Negeri 2 Kuripan is still a large computer networks and complex. With the computer network conditions like this, it causes traffic in computer networks become dense eventually cause some problems such as access to an application to be slow. Under these conditions, then the computer network in SMK Negeri 2 Kuripan requires a segmentation of the network / subnetwork according to the needs of the organization.

Computer networks in SMK Negeri 2 Kuripan is still using a single network ID, so as to make the segmentation of networks of smaller needed a way to break the single Network ID into a Network ID. Subnetting is a way to break up the Network ID is by using hostid bits to form part subnetID. Subnetting process is done on a single Network ID is produced 11 subnet that has been established based on the needs of organizations SMK Negeri 2 Kuripan.

Utilization of Virtual LAN topologies for the physical design and subnetting for logic design is able to provide optimization of the performance of computer networks. Optimization is achieved due to the use of VLAN network can reduce the collision data (collision) by blocking packets / frames that do not need to be outstanding in the network. In addition, VLANs can also be split in / out broadcast domain, so that data packets sent from a host will only be forwarded to the destination host and other hosts will not accept packets / frames.
\end{abstract}

Keywords: computer networks, linux, vlan, subnetting, switch manageable

\begin{abstract}
Abstrak
Dalam mewujudkan layanan terintegrasi baik secara internal maupun eksternal, SMK Negeri 2 Kuripan membutuhkan infrastruktur jaringan komputer yang andal dan dapat menghubungkan semua unit dalam satu jaringan terintegrasi. Keadaan jaringan komputer saat ini di SMK Negeri 2 Kuripan masih merupakan jaringan komputer yang besar dan kompleks. Dengan kondisi jaringan komputer seperti ini, hal itu menyebabkan traffic di jaringan komputer menjadi padat akhirnya menyebabkan beberapa masalah seperti akses ke suatu aplikasi menjadi lambat. Dengan kondisi tersebut, maka jaringan komputer di SMK Negeri 2 Kuripan membutuhkan segmentasi jaringan / subnetwork sesuai dengan kebutuhan organisasi.

Jaringan komputer di SMK Negeri 2 Kuripan masih menggunakan ID jaringan tunggal, sehingga membuat segmentasi jaringan yang lebih kecil diperlukan cara untuk memecah ID Jaringan tunggal menjadi Network ID. Subnetting adalah cara untuk memecah ID Jaringan dengan menggunakan bit hostid untuk membentuk bagian subnetID. Proses subnetting yang dilakukan pada satu Network ID dihasilkan 11 subnet yang telah ditetapkan berdasarkan kebutuhan organisasi SMK Negeri 2 Kuripan.

Pemanfaatan topologi LAN Virtual untuk desain fisik dan subnetting untuk desain logika mampu memberikan optimalisasi kinerja jaringan komputer. Optimasi tercapai karena penggunaan jaringan VLAN dapat mengurangi data tabrakan (collision) dengan memblokir paket / frame yang tidak perlu beredar di jaringan. Selain itu, VLAN juga dapat dibagi dalam / keluar domain broadcast, sehingga paket data yang dikirim dari host hanya akan diteruskan ke host tujuan dan host lain tidak akan menerima paket / frame.
\end{abstract}

Kata kunci: jaringan komputer, linux, vlan, subnetting, switch manageable 


\section{Pendahuluan}

Ilmu pengetahuan dan teknologi informasi berkembang cukup pesat dan menghasilkan inovasi-inovasi baru yang senantiasa terus berubah ke arah yang lebih baik. Informasi menjadi kata kunci dalam berbagai aspek kehidupan. Siapa yang dapat menguasai informasi, baik penguasaan dalam proses penyajian, maupun mendapatkan, ia akan bisa tampil survive di tengah persaingan yang sedemikian ketat. Dengan alasan inilah perhatian terhadap proses informasi menjadi sangat di tekankan. SMKN 2 Kuripan merupakan sekolah menengah kejuruan yang berbasis pada bidang teknologi dan industri. Jurusan yang tersedia di sekolah ini antara lain Teknik Otomotif, Audio Video, Konstruksi Bangunan, Mesin Perkakas, Mesin Pendingin, serta Komputer dan Jaringan. Guna menunjang proses belajar mengajar, SMKN 2 Kuripan memiliki empat laboratorium yang terhubung menggunakan jaringan kabel. Tiga laboratorium digunakan sebagai laboratorium Jaringan Komputer bagi Teknik Komputer dan Jaringan, sedangkan laboratorium yang lainnya digunakan sebagai laboratorium KKPI bagi semua program keahlian. Keempat laboratorium tersebut terhubung satu sama lain dan berada dalam satu alamat jaringan yang sama yaitu 192.168.1.0/24, dimana perangkat yang digunakan untuk menghubungkannya adalah switch unmanageable 16 port. Laboratorium komputer ini juga dulunya terhubung dengan jaringan internet, tetapi karena perangkat yang digunakan untuk menghubungkan dengan internet mengalami kerusakan, sehingga untuk saat ini jaringan laboratorium SMKN 2 Kuripan tidak dapat terhubung dengan internet.

\section{Tinjauan Pustaka}

Puspito, dkk (2014), dalam penelitiannya menyatakan ada beberapa keunggulan jaringan VLAN, antara lain dapat mengelola switch managable. Dari segi flexibility, user pada jaringan VLAN yang sama tidak bergantung pada letak fisik atau lokasi user berada. Dari segi availability, penggunaan VLAN juga memberikan tingkat keamanan yang lebih tinggi, karena setiap user tidak bisa begitu saja masuk ke dalam switch dan bergantung dengan user lain. Disamping itu dalam mendistribusikan jaringan lebih termanajemen, dan dalam penggunaan VTP dapat menghemat dalam penggunaan kabel jaringan.

Pantu, dkk (2015) merancang jaringan VLAN menggunakan model hierarchical. Lapisan logis untuk distribusi data dibagi menjadi dua yaitu lapisan core/distribution dan lapisan access. Routing antar VLAN menggunakan model routing "router-on-a-stick using trunk" sehingga workstation antar VLAN dapat terhubung hanya dengan menggunakan satu buah router. Dengan menggunakan metode simulasi pada pengujian rancangan, diketahui bahwa workstation antar VLAN berhasil terkoneksi satu sama lain dan server berfungsi dengan baik.

Penelitian oleh Nugraha dan Widodo (2014), dengan VLAN diharapkan informasi dapat terkirim dalam satu jaringan dengan memanfaatkan perangkat keras seperti switch manageable, router, server VoIP dan IPCAM. Pengujian jaringan dengan video streaming menggunakan peralatan IPCAM, VoIP call dalam VLAN sama, dan VoIP call dalam VLAN yang berbeda. Implementasi jaringan VLAN dapat dipakai untuk mengirim data suara dan video streaming dengan kualitas yang baik.

\section{Virtual LAN}

Virtual Local Area Network (VLAN) merupakan suatu model jaringan yang tidak terbatas pada lokasi fisik seperti Local Area Network (LAN), hal ini mengakibatkan suatu network dapat dikonfigurasi secara virtual tanpa harus menuruti lokasi fisik peralatan.

\subsection{Konsep Kerja VLAN}

VLAN diklasifikasikan berdasarkan metode (tipe) yang digunakan untuk mengklasifikasikan nya, baik menggunakan port, MAC address dsb. Semua informasi yang mengandung penandaan/ pengalamatan suatu VLAN (tagging) di simpan dalam suatu database (tabel). Jika penandaan nya berdasarkan port yang digunakan maka database harus mengindikasi kan port-port yang digunakan oleh VLAN. Untuk mengaturnya maka biasanya digunakan switch/bridge yang manageable atau yang bisa di atur.

\subsection{Link VLAN}

VLAN dibangun menggunakan berbagi perangkat, seperti: switch, router, PC dan sebagainya. Tentunya diperlukan hubungan atau link diantara perangkat-perangkat tersebut. Link seringkali disebut sebagai interface. Ada dua jenis link yang digunakan, yaitu:

\section{Access Link}

Access link merupakan tipe link yang umum dan dimiliki oleh hampir semua jenis switch VLAN. Accesslink lazimnya digunakan untuk menghubungkan komputer dengan switch. Access link tidak lain merupakan port switch yang sudah terkonfigurasi. Selama proses transfer data, switch akan membuang informasi tentang VLAN. Anggota suatu VLAN tidak bisa berkomunikasi dengan anggota VLAN yang lain, 
kecuali jika dihubungkan oleh router. Access link mendukung teknologi Ethernet biasa (10Mbps) hingga Fast Ethernet (100Mbps).

\section{Trunk Link}

Istilah Trunk diambil dari system telepon yang dapat mengangkut beberapa percakapan sekaligus (multiple conversation). Trunk Link digunakan untuk menghubungkan switch dengan switch yang lain, switch dengan router, atau switch dengan server. Jadi, port telah dikonfigurasi untuk dilalui berbagai VLAN (tidak hanya sebuah VLAN). TrunkLink hanya mendukung teknologi Fast (100Mbps) Ethernet atau Gigabit (1000Mbps) Ethernet. Sebab Trunk Link lazimnya dihubungkan dengan network backbone berkecepatan tinggi. Wajar jika kebutuhannya lebih tinggi dibandingkan Access Link. (Sofana, 2010).

Untuk memudahkan memahami kedua link tersebut, bayangkan Access Link seperti jalan menuju pekarangan rumah, sedangkan Trunk Link seperti jalan umum. Lazimnya, jalan umum boleh dilalui oleh semua pengguna jalan. Sedangkan jalan menuju pekarangan rumah hanya dilalui oleh pemilik rumah atau mereka yang berkunjung ke rumah tersebut. (Sofana, 2010).

\section{Analisa}

\subsection{Analisa Sistem}

Analisis data adalah tahap dalam mencari solusi atau jalan keluar terhadap permasalahan yang ada. Dalam mengamati, mempelajari dan menganalisis sistem yang berjalan pada jaringan komputer SMKN 2 Kuripan, maka diketahui beberapa permasalahan yang ada pada jaringan tersebut yaitu:

1. Jaringan komputer yang terdapat pada seluruh laboratorium masih berada dalam satu alamat jaringan yang sama.

2. Terdapat komputer yang tidak dipergunakan secara optimal. Komputer tersebut tidak digunakan karena spesifikasi dari sistem komputerisasi saat ini tidak mampu didukung oleh Pentium 4 sehingga komputer-komputer baru mulai digunakan sebagai pengganti dari Pentium 4 tersebut. Komputer tersebut memiliki prosessor Intel Pentium 4, memori DDR $1024 \mathrm{Mb}$, dan harddisk $20 \mathrm{~GB}$.

3. Pihak pengelola laboratorium komputer menginginkan setiap laboratorium dibagi menjadi VLAN agar memudahkan dalam memanajemen setiap VLAN, dimana untuk pengalamatan IP address setiap VLAN yang akan digunakan adalah IP private kelas C. Pengelola juga berkeinginan agar setiap
VLAN dikonfigurasi sehingga bisa saling berkomunikasi satu sama lain hanya melalui komputer tertentu di masing-masing VLAN.

4. Pengelola berharap perangkat komputer pentium 4 yang tersedia bisa dipergunakan secara maksimal untuk mendukung manajemen VLAN.

5. Untuk memudahkan dalam melakukan ujicoba fungsional dari switch manageable yang dibangun, dilakukan dengan membuat aplikasi pendukung dari switch manageable yang bersifat optional dimana nantinya aplikasi pendukung tersebut juga bisa dipergunakan oleh pihak pengelola switch manageable dalam mempermudah memanajemen VLAN.

\subsection{Identifikasi Masalah}

Untuk menangani pengelompokkan VLAN dari masing-masing laboratorium, maka akan dibangun sebuah switch manageable yang memanfaatkan komputer pentium 4 yang terdapat pada SMKN 2 Kuripan. Dalam membangun switch manageable dibutuhkan PC dengan spesifikasi minimal Pentium IV RAM 1 $\mathrm{GB}$, harddisk minimal $10 \mathrm{~GB}$ dan dilengkapi dengan minimal 2 kartu jaringan (NIC).

\subsection{Mengkodekan Sistem Operasional}

Setelah melakukan tahapan perancangan sistem selanjutnya adalah melakukan tahapan konfigurasi dan pengkodean. Tahapan ini merupakan tahapan inti dari proses pembangunan switch manageable.

\subsubsection{Konfigurasi Dasar}

Konfigurasi ini merupakan konfigurasi awal yang dilakukan untuk mempersiapkan sistem ke tahap selanjutnya. Konfigurasi yang dilakukan pada tahapan ini antara lain sebagai berikut:

1. Menonaktifkan SELinux

Menonaktifkan servis SELinux yang terdapat pada switch manageable.

2. Mengatur Parameter pada File /etc/sudoers Memberikan hak akses penuh pada user apache agar bisa menjalankan perintahperintah root pada sistem switch manageable.

3. Menginstal paket telnet

Melakukan instalasi paket telnet agar bisa mengakses switch manageable menggunakan telnet dari computer klien.

4. Mengatur parameter pada file httpd.conf Mengatur parameter pada file httpd.conf yang berada pada direktori /etc / httpd / conf/ httpd.conf agar aplikasi pendukung 
switch manageable dapat diakses melalui komputer klien.

5. Mengatur hak akses port pada firewall Mengatur hak akses port yang akan digunakan untuk mengakses switch manageable melalui komputer klien, diantaranya port 23 dan port 80.

6. Mengaktifkan Packet Forwarding Mengatur nilai parameter dari packet forwarding agar dapat melewatkan paket data.

\subsubsection{Konfigurasi Manajemen VLAN}

Konfigurasi ini merupakan proses pembuatan fitur VLAN yang akan dibangun di dalam sistem switch manageable. Konfigurasi yang dilakukan antara lain sebagai berikut:

1. Menginstalasi Paket bridge-util Melakukan instalasi paket bridge-util untuk membuat fungsi bridge pada sistem switch manageable.

2. Membuat Bridge

Membuat bridge pada sistem switch manageable.

3. Melakukan Load modul VLAN 8021q Me-load modul VLAN untuk dapat mengaktifkan fungsi VLAN.

4. Membuat Ethernet VLAN

Membuat ethernet VLAN untuk setiap ethernet yang terdapat didalam switch manageable.

5. Memberikan IP address default untuk switch manageable

Memberikan alamat IP default pada switch manageable agar bisa diakses melalui komputer klien.

\subsection{Menguji Sistem Operasional}

Tahapan ini merupakan tahapan yang dilakukan untuk memverifikasi dan menguji coba hasil konfigurasi sehingga dapat mengetahui tingkat keberhasilan dari switch manageable yang dibangun. Verifikasi dilakukan pada konfigurasi yang telah dibuat. Sedangkan ujicoba dilakukan menggunakan beberapa skenario pengujian.

\subsection{Verifikasi Konfigurasi}

Verifikasi yang dilakukan untuk mengecek hasil konfigurasi yang dilakukan pada tahap sebelumnya. langkah verifikasi konfigurasi yang akan dilakukan antara lain:

1. Memverifikasi ethernet jaringan yang digunakan dengan utilitas ifconfig.

2. Memverifikasi parameter-parameter dari setiap ethernet menggunakan utilitas cat.

3. Memverifikasi status service xinetd telah aktif menggunakan perintah service xinetd status.

4. Memverifikasi aturan iptables menggunakan perintah iptables $-L$.
5. Melakukan ujicoba koneksi dari komputer klien ke switch manageable menggunakan utilitas ping.

\subsection{Skenario Ujicoba Prototype}

Ujicoba ini akan menggunakan jaringan yang dirancang dan dibuat sebagai rancangan Prototype uji coba, hal ini dikarenakan banyaknya jumlah komputer klien yang terdapat pada masing-masing laboratorium. Adapun desain jaringan yang akan digunakan untuk ujicoba skala laboratorium sebagai Prototype melibatkan 2 laboratorium dari 4 laboratorium yang terdapat di SMKN 2 Kuripan. Laboratorium yang di libatkan yakni laboratorium TKJ dan laboratorium KKPI

\section{Hasil Penelitian dan Pembahasan}

\subsection{Implementasi Sistem}

Setelah melakukan tahapan perancangan sistem selanjutnya adalah melakukan tahapan konfigurasi dan pengkodean. Tahapan ini merupakan tahapan inti dari proses pembangunan switch manageable. Konfigurasi dan pengkodean yang dilakukan pada sistem switch manageable dilakukan sebagai berikut:

1. Konfigurasi Dasar

Konfigurasi ini merupakan konfigurasi awal yang dilakukan untuk mempersiapkan sistem ke tahap selanjutnya.

2. Konfigurasi Ethernet

Sebelum ethernet yang ada pada switch manageable digunakan, terlebih dahulu diperlukan beberapa konfigurasi parameter yang terkait dengan setiap ethernet. Langkah pengaturan parameter tersebut adalah sebagai berikut:

1) Berpindah ke dalam direktori /etc /sysconfig/network-scripts yang memuat konfigurasi jaringan.

2) Membuka file ifcfg-etho menggunakan editor nano. Mengubah parameter ONBOOT yang berfungsi untuk mengaktifkan file ifcfgetho secara otomatis ketika komputer di hidupkan. Dan parameter NM_CONTROLLED yang berfungsi untuk memberikan pengaturan pada parameter yang terkait dengan setiap ethernet.

Langkah pengaturan parameter tersebut adalah sebagai berikut: Berpindah ke dalam direktori /etc/sysconfig/network-scripts yang memuat konfigurasi jaringan. Membuka file ifffg-etho menggunakan editor nano. Mengubah parameter ONBOOT yang berfungsi untuk mengaktifkan file ifcfg-etho secara otomatis ketika komputer dihidupkan. Dan parameter 
NM_CONTROLLED yang berfungsi untuk memberikan pengaturan pada Network Manager untuk ethernet etho.

\subsection{Hasil Ujicoba Di Lokasi Penelitian}

Ujicoba langsung melibatkan 2 (dua) laboratorium dari total keseluruhan 4 (empat) laboratorium yang terdapat di SMKN 2 Kuripan. Laboratorium yang dilibatkan yaitu laboratorium TKJ dan laboratorium KKPI, dikarenakan slot eksternal yang terdapat pada switch manageable hanya mampu menampung dua buah kartu interface jaringan saja sehingga setiap interface yang terdapat pada switch manageable akan menangani 1 jaringan laboratorium. Memverifikasi file konfigurasi bridge pada switch manageable menggunakan telnet melalui komputer host. Pada komputer host, buka command prompt lalu ketik telnet 192.168.1.1, login dengan "centos" dan password “123456”.

$\left[\begin{array}{l}\text { Cent Telnet 192.168.1.1 } \\ \text { Cent0S release 6.4 (Final) } \\ \text { Kernel 2.6.32-358.el6.i686 on an } \mathrm{i} 686 \\ \text { login: centos } \\ \text { Password: } \\ \text { Last login: Hon Apr } 717: 32: 53 \text { from 192.168.2.3 } \\ \text { [centos@centos "]\$. }\end{array}\right.$

Gambar 5.1 Login Telnet ke switch manageable

Setelah masuk kedalam sistem switch manageable, masuk sebagai superuser dengan menggunakan perintah $s u$. Lalu berpindah ke direktori / etc / sysconfig / network-scripts / dimana file br20 dan br30 tersimpan. Gunakan perintah ls untuk melihat isi direktori.

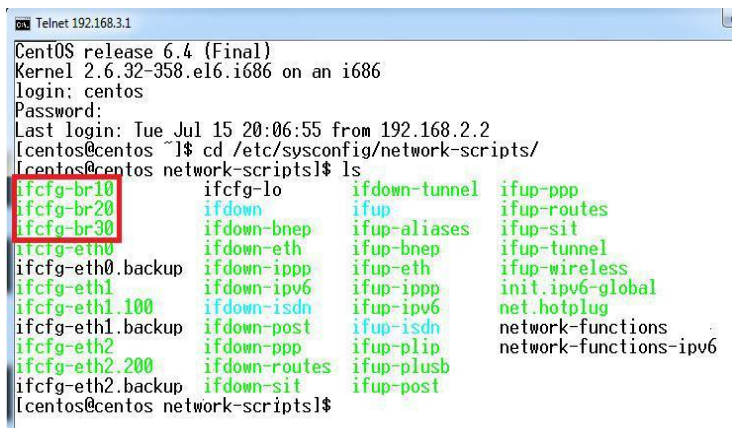

Gambar 5.2. Verifikasi file bridge

Pada gambar 5.2. verifikasi file bridge terlihat penambahan file bridge ifcfg-br10, ifcfgbr20 dan ifffg-br30 pada direktori / etc / sysconfig / network-scripts/. Ini menandakan bahwa penambahan file bridge melalui aplikasi pendukung juga akan menambahkan file bridge keda lam parameter yang telah diinputkan menggunakan aplikasi pendukung pada bridge menggunakan utilitas cat dengan perintah cat ifcfg-br1, cat ifcfg-br20 dan cat ifcfg-br30.

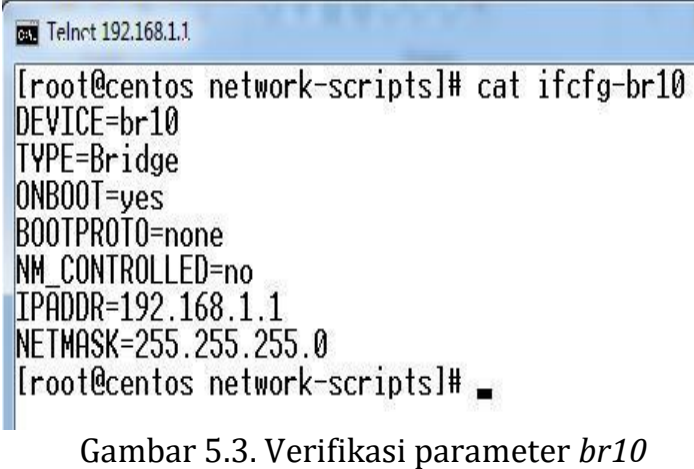

Cis. Telnet 192.168.1.1

[root@centos network-scripts]\# cat ifcfg-br20 DEVICE $=$ br 20 TYPE=Bridge ONBOOT=yes BOOTPROT0 =none NH_CONTROLLED=no IPĀDDR=192.168.2.1

NETMASK $=255.255 .255 .0$

[root@centos network-scripts]\# .

Gambar 5.4. Verifikasi parameter br20

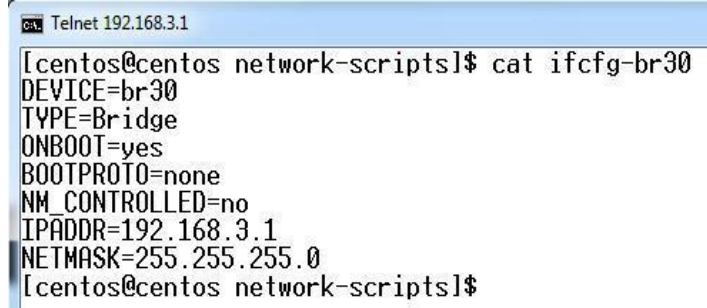

Gambar 5.5. Verifikasi parameter br30

Pada gambar 5.3,5.4,5.5. terlihat bahwa masing-masing filebridge yang dibuat menggunakan aplikasi memiliki alamatIP sesuai dengan alamat IP yang diinputkan melalui aplikasi pendukung. Memverifikasi ethernet yang masuk kedalam keanggotaan bridge. Pada saat membuat bridge br200, ethernet yang menjadi anggota dari br200 adalah eth1. Gunakan utilitas cat dengan perintah cat ifcfg eth1 untuk melihat penambahan parameter BRIDGE didalam file etho.

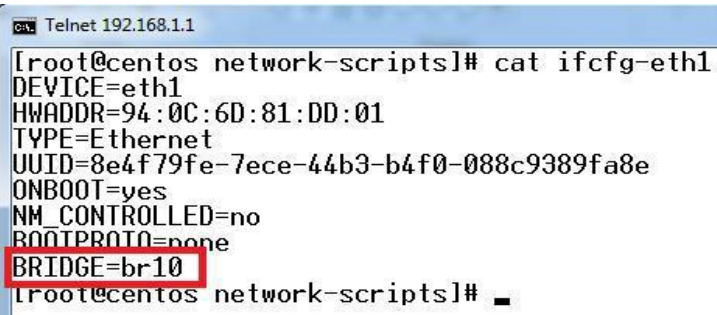

Gambar 5.6 Verifikasi parameter eth1 
Pada gambar 5.6. terlihat penambahan parameter BRIDGE dengan nilai br10 pada file ifcfg-eth1. Ini membuktikan bahwa eth1 telah menjadi anggota dari br100. Sedangkan pada bridge br20, ethernet yang menjadi anggota adalah eth2. Gunakan utilitas cat dengan perintah cat ifffg eth2 untuk melihat penambahan parameter BRIDGE didalam file eth2.

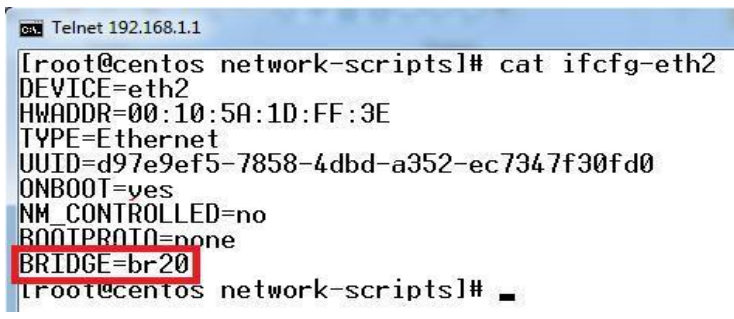

\section{Gambar 5.7. Verifikasi parameter eth2}

Pada gambar 5.7 verifikasi Parameter terlihat penambahan parameter BRIDGE dengan nilai $b r 20$ pada file ifffg-eth2. Ini membuktikan bahwa eth2 telah menjadi anggota dari br20.

Melakukan uji koneksi dari komputer host laboratorium ke switch manageable. Pada masing-masing client yang telah diberi alamat IP address dilakukan uji konektifitas pada masingmasing gateway interface dari switch manageable yang terhubung langsung dengan jaringan tersebut. Ujicoba menggunakan utilitas ping pada command prompt dengan perintah ping 192.168.2.1 untuk client pada laboratorium KKPI.

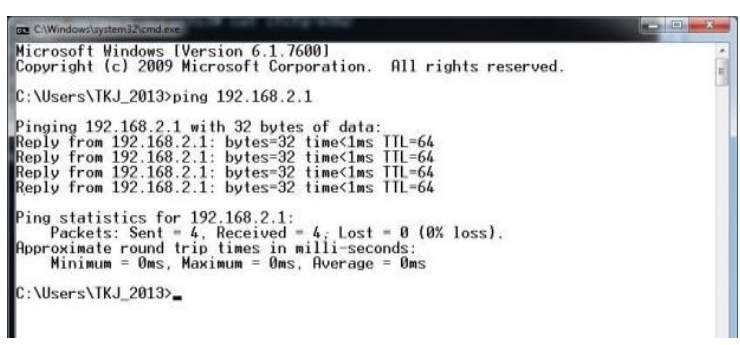

Gambar 5.8. Verifikasi ping ke gateway

Jika berhasil maka client dimasing-masing laboratorium telah terhubung dengan switch. Setelah itu mencoba melakukan uji konektifitas antar jaringan yang berbeda (VLAN) dari client laboratorium Jaringan ke client laboratorium KKPI. Ujicoba menggunakan utilitas ping pada command prompt dengan tujuan komputer host laboratorium Jaringan dengan perintah ping 192.168.1.2 melalui klien pada laboratorium KPI.

\section{Kesimpulan}

Dari hasil uraian pembahasan sebelumnya dan pengujian yang dilakukan, dapat disimpulkan beberapa hal sebagai berikut:
1. Berdasarkan hasil ujicoba pada jaringan laboratorium SMK Negeri 2 Kuripan, switch manageable mampu membantu administrator jaringan dalam melakukan pengelolaan terhadap jaringan Virtual LAN SMKN 2 Kuripan. Pengelolaan yang di lakukan berupa pembuatan bridge, pembuatan ethernet VLAN dan penerapan iptables sebagai firewall.

2. Berdasarkan pengujian terhadap pengguna terutama administrator jaringan SMKN 2 Kuripan, aplikasi pendukung switch manageable dapat dioperasikan dengan mudah.

3. Switch manageable dapat membatasi komunikasi antar komputer yang terdapat didalam jaringan VLAN, membatasi komputer yang dapat mengakses switch manageable, dan dapat memberikan fungsi sharing files and folders untuk komputer yang memiliki hak komunikasi didalam jaringan maupun antar jaringan VLAN.

\section{Daftar Pustaka}

Novriansyah, N., 2000. LINUX, PT Elex Media Komputindo, Jakarta

Nugraha, F.S., Widodo, S, 2014, Perencanaan dan Implementasi Virtual Local Area Network untuk Komunikasi Video Streaming dan Suara, JTET, Vol. 3, No. 1, April 2014, Politeknik Negeri Semarang, Semarang.

Pantu, Y., Iswahyudi, C., Rahmawati K, R.Y., 2015, Analisis Dan Perancangan VLAN Pada Dishubkominfo Kabupaten Manggarai Menggunakan Cisco Packet Tracer, Jurnal JARKOM Vol. 3 No. 1, Desember 2015, Institut Sains dan Teknologi AKPRIND, Yogyakarta

Puspito, F., Widyastuti, Hj. N., Triyono, J., 2014, Perancangan Blue Print Jaringan Menggunakan Virtual Lan (VLAN) dengan studi kasus PT. PLN Persero Area Kudus, Jurnal JARKOM Vol. 1 No. 2, Juni 2014, Institut Sains dan Teknologi AKPRIND, Yogyakarta

Rafiudin, R.. 2006. IP Routing dan Firewall dalam Linux, C.V. Andi Offset, Yogyakarta

Sofana, I., 2010, CISCO CCNA dan jaringan komputer, Informatika Bandung, Bandung

Sofana, I., 2008. Membangun Jaringan Komputer, Informatika Bandung, Bandung

Sofana, I., 2010, Mudah Belajar Linux, Informatika Bandung, Bandung

Syafrizal, M., 2005, Pengantar Jaringan Komputer, C.V. Andi Offset, Yogyakarta

Towidjojo, R., 2013, Mikrotik Kung Fu (Kitab 2), Jasakom, Jakarta 
Tantoni, Ahmad, Arief Setyanto, and Eko Pramono. "ANALISIS DAN PERANCANGAN BLUEPRINT INFRASTRUKTUR JARINGAN KOMPUTER UNTUK MENDUKUNG IMPLEMENTASI SISTEM INFORMASI PADA STMIK LOMBOK." Informasi Interaktif 3.1 (2018): 74-83.
Hairul Fahmi. "Efektifitas Wireless Lan Berbasis 802.11 b/g Sebagai Solusi Jaringan Kampus (Studi Kasus: Sekolah Tinggi Agama Hindu (STAHN) Gde Pudja Mataram." IJNS-Indonesian Journal on Networking and Security 4.4 (2015). 